Delft University of Technology

\title{
Nanorods grown by copper anodizing in sodium carbonate
}

Stepniowski, Wojciech; Paliwoda, Damian ; Abrahami, Shoshan; Michalska-Domańska, Marta; Landskron, Kai; Buijnsters, Ivan; Mol, Arjan; Terryn, Herman; Misiolek, Wojciech Z.

DOI

10.1016/j.jelechem.2019.113628

Publication date

2020

Document Version

Final published version

Published in

Journal of Electroanalytical Chemistry

\section{Citation (APA)}

Stepniowski, W., Paliwoda, D., Abrahami, S., Michalska-Domańska, M., Landskron, K., Buijnsters, I., Mol, A., Terryn, H., \& Misiolek, W. Z. (2020). Nanorods grown by copper anodizing in sodium carbonate. Journal of Electroanalytical Chemistry, 857, [113628]. https://doi.org/10.1016/j.jelechem.2019.113628

\section{Important note}

To cite this publication, please use the final published version (if applicable).

Please check the document version above.

\section{Copyright}

Other than for strictly personal use, it is not permitted to download, forward or distribute the text or part of it, without the consent of the author(s) and/or copyright holder(s), unless the work is under an open content license such as Creative Commons.

Takedown policy

Please contact us and provide details if you believe this document breaches copyrights.

We will remove access to the work immediately and investigate your claim. 
Green Open Access added to TU Delft Institutional Repository

'You share, we take care!' - Taverne project

https://www.openaccess.nl/en/you-share-we-take-care

Otherwise as indicated in the copyright section: the publisher is the copyright holder of this work and the author uses the Dutch legislation to make this work public. 


\title{
Nanorods grown by copper anodizing in sodium carbonate
}

\author{
Wojciech J. Stępniowski ${ }^{\text {a,b,c,d,*, Damian Paliwoda }}{ }^{\mathrm{e}, \mathrm{h}}$, Shoshan T. Abrahami ${ }^{\mathrm{f}}$, \\ Marta Michalska-Domańska ${ }^{\text {a,g }}$, Kai Landskron ${ }^{\text {e }}$, Josephus G. Buijnsters ${ }^{\text {b }}$, Johannes M.C. Mol ${ }^{\text {a }}$, \\ Herman Terryn $^{\mathrm{a}, \mathrm{f}}$, Wojciech Z. Misiolek ${ }^{\mathrm{c}}$ \\ ${ }^{a}$ Department of Materials Science and Engineering, Faculty 3mE, Delft University of Technology, Mekelweg 2, 2628, CD, Delft, the Netherlands \\ ${ }^{\mathrm{b}}$ Department of Precision and Microsystems Engineering, Faculty 3mE, Delft University of Technology, Mekelweg 2, 2628, CD, Delft, the Netherlands \\ ${ }^{\mathrm{c}}$ Department of Materials Science and Engineering \& Loewy Institute, Lehigh University, 5 East Packer Ave, 18015, Bethlehem, PA, United States \\ d Department of Advanced Materials and Technologies, Faculty of Advanced Technology and Chemistry, Military University of Technology, 2 Kaliskiego Str., 00908, \\ Warsaw, Poland \\ e Department of Chemistry, Lehigh University, 6 East Packer Avenue, 18015, Bethlehem, PA, United States \\ ${ }^{\mathrm{f}}$ Research Group of Electrochemical and Surface Engineering (SURF), Vrije Universiteit Brussel, Pleinlaan 2, 1050, Brussels, Belgium \\ ${ }^{\mathrm{g}}$ Institute of Optoelectronics, Military University of Technology, 2 Kaliskiego Str., 00908, Warsaw, Poland \\ h National Synchrotron Radiation Centre SOLARIS, Jagiellonian University, Czerwone Maki 98, 30392, Kraków, Poland
}

\section{A R T I C L E I N F O}

\section{Keywords:}

Anodization

Self-organization

Nanorods

Copper oxides

Passivation

\begin{abstract}
A B S T R A C T
Self-organized anodization of copper in $0.1 \mathrm{M} \mathrm{Na}_{2} \mathrm{CO}_{3}$ electrolyte was studied in order to obtain nanostructured oxide surface on the metal substrate. Linear sweep voltammetry (LSV) revealed that the most suitable voltage range for anodic film formation is from 3 to $31 \mathrm{~V}$. In this range (except between 3 and $7 \mathrm{~V}$ ), the oxide is formed as nanorods, with the diameter of the anodically grown nanostructures increasing with the applied voltage. The smallest diameter of the nanorods was found to be $28 \pm 9 \mathrm{~nm}(15 \mathrm{~V})$, while the greatest diameter was $109 \pm 15 \mathrm{~nm}$ (30 V). X-ray photoelectron spectroscopy (XPS), X-ray diffraction (XRD) and Raman spectroscopy pointed out that the nanorods consist of crystalline $\mathrm{CuO}$ (tenorite) and $\mathrm{Cu}_{2} \mathrm{O}$ (cuprite), and amorphous $\mathrm{Cu}(\mathrm{OH})_{2}$. Moreover, the greater the anodizing voltage, the greater the $\mathrm{CuO}$ content versus $\mathrm{Cu}_{2} \mathrm{O}$. The formed nanostructured materials may find applications in photocatalysis and catalytic electrochemical reduction of carbon dioxide into light hydrocarbons.
\end{abstract}

\section{Introduction}

Anodization is a well-known process of corrosion protection of light metals and their alloys [1,2]. This process was also found to be extremely important for nanotechnology, when Masuda and Fukuda reported their results on two-step, self-organized anodizing, resulting in the formation of highly ordered, hexagonally-arranged nanoporous alumina [3]. Currently, self-organized anodization of aluminum and transition metals allows growing nanostructured materials with tailored morphologies that can be utilized in a wide range of disciplines. For example, application of hexagonally-arranged nanoporous alumina allows the production of a wide range of nanostructures (nanowires, nanotubes, nanodots) [4] for optical [5] and electrochemical sensors [6], the generation of various colors by modifying their morphology $[7,8]$ and tuning of the surface wetting (i.e., water contact angle) by effective control of the surface porosity $[9,10]$. Nanotubular and nanoporous titania can be used in dye sensitized solar cells [11], perform photocatalytic $\mathrm{CO}_{2}$ conversion into light hydrocarbons [12], make progress in photoelectrochemical water splitting [13] and contribute in efficient drug releasing platforms [14]. Similarly, anodic tungsten oxide enables photoelectrochemical splitting of water $[15,16]$. These anodically produced oxides are generally amorphous, made of hexagonally arranged nanopores or nanotubes and have stoichiometric, or very close to the stoichiometry, ratios of the chemical constituent elements, like $\mathrm{Al}_{2} \mathrm{O}_{3}, \mathrm{WO}_{3}$, or $\mathrm{TiO}_{2}$.

The anodic oxides grown on copper differ from the previously mentioned anodic oxides of other metals. They are composed of mixed $\mathrm{Cu}_{2} \mathrm{O}, \mathrm{CuO}$ and $\mathrm{Cu}(\mathrm{OH})_{2}$ [17] (due to two common oxidation states of copper), are crystalline $[17,18]$ and are typically made of high aspect ratio nano-needles, not nanopores or nanotubes [17-22]. However, their specific morphology and band gaps (2.1-3.8 eV and 1.2-2.2 eV for $\mathrm{Cu}_{2} \mathrm{O}$

\footnotetext{
* Corresponding author. Department of Materials Science and Engineering, Faculty 3mE, Delft University of Technology, Mekelweg 2, 2628, CD, Delft, the Netherlands.

E-mail addresses: wos218@lehigh.edu, wojciech.stepniowski@wat.edu.pl (W.J. Stępniowski).
} 
and $\mathrm{CuO}$, respectively) [17,23] make them interesting materials for photoelectrochemical water splitting and heterojunction solar cells (namely $\mathrm{Cu}_{2} \mathrm{O}$ with $\mathrm{ZnO}$ heterojunction [24]). Furthermore, the anodically grown nano-needles have already found applications in high-contact angle surfaces [20], photocatalysis [19], corrosion protection [22] and glucose sensing [25].

Surprisingly, anodization of copper has been performed mainly in $\mathrm{NaOH}$ [26-28] or KOH [18-22] based electrolytes, whereas the Pourbaix diagram for copper shows that passivity is possible even at neutral $\mathrm{pH}$ [29]. Also, solutions of salts with alkaline hydrolysis would be attractive electrolytes. Thus, anodization of copper in potassium oxalate [25] and potassium carbonate [30] are the only reported examples in the literature. Additionally, in the majority of the cases, anodization of copper is being performed with potentiostats and consequently three-electrode systems, not by the classical two-electrode approach for anodizing. In view of the need for process robustness and insights in obtainable surface nanostructures, a systematic study of the influence of the operating conditions on the morphology and chemical composition of the grown nanostructured oxides on copper are of pivotal importance. What is more, anodization of copper in a two-electrode system is easy to scale up, while copper nanostructures are strongly demanded in such emerging applications like electrochemical carbon dioxide reduction into hydrocarbons and their derivatives.

The above mentioned findings motivated the study reported in this paper. Herein, a systematic study of the nanostructured oxides grown in $0.1 \mathrm{M} \mathrm{Na}_{2} \mathrm{CO}_{3}$ using a simple, two-electrode system is presented. Results are examined in terms of electrochemical response, oxide morphology, chemical and phase composition. The main aim of the presented research is to explore new, lower $\mathrm{pH}$, electrolyte and new regime for the formation of nanostructures by copper anodizing.

\section{Experimental}

\subsection{Sample preparation}

A high purity copper ( $>99.99 \%$ KGHM Polska Miedź) was cut into coupons $\left(25 \times 10 \mathrm{~mm}^{2}\right)$ and degreased (acetone and subsequently ethanol). Then, the coupons were electropolished in $10 \mathrm{M} \mathrm{H}_{3} \mathrm{PO}_{4}$ at $7.5 \mathrm{~V}$ (SM120-25 Delta Elektronika power supply) for $60 \mathrm{~s}$ at room temperature. Such prepared samples were coated at the back and edges with an acid resistant paint, leaving an exposed working surface area of $1 \mathrm{~cm}^{2}$.

To find the useful voltage range for copper anodization in $0.1 \mathrm{M}$ $\mathrm{Na}_{2} \mathrm{CO}_{3}$, linear sweep voltammetry was performed from 0 to $100 \mathrm{~V}$ with a sweep rate of 0.1 V/s (SM120-25 Delta Elektronika power supply).

Self-organized anodization of the copper samples was conducted in a double-walled electrochemical cell, plugged into a thermostat with circulator (Huber) at voltage ranging from 3 to $31 \mathrm{~V} \mathrm{(4V} \mathrm{step} \mathrm{from} 3$ to $31 \mathrm{~V}$; SM120-25 Delta Elektronika power supply) at $20^{\circ} \mathrm{C}$ for $1 \mathrm{~h}$.

\subsection{Characterization of the samples}

\subsubsection{Scanning electron microscopy (SEM)}

Field emission scanning electron microscopy (FE-SEM; Hitachi 4300) was used to examine the samples. A thin layer of Iridium was DCsputtered on the samples to improve the surface conductivity. Determination of the diameter of the grown nanostructures was done using Quartz PCI software. At least 50 direct measurements were performed to determine the nanostructure diameter. The diameter is given as an average \pm standard deviation.

\subsubsection{X-ray photoelectron spectroscopy (XPS)}

XPS spectra were collected using a PHI5600 photoelectron spectrometer (Physical Electronics) with an Al $K \alpha$ monochromatic X-ray source ( $1486.71 \mathrm{eV}$ of photons). The vacuum in the analysis chamber was approximately $5 \times 10^{-9}$ Torr during measurements. Survey $(0-1400 \mathrm{eV})$ spectra were recorded each time, before high-resolution $(23.5 \mathrm{eV}$ pass energy and step size of $0.1 \mathrm{eV}$ ) scans of the main photoelectron peaks were obtained. These measurements were recorded from $800 \mu \mathrm{m}^{2}$ area at takeoff angle of $15^{\circ}$ with respect to the sample surface. The data reported here are taken from one spot on each surface; however, these results were compared to three other spectra measured on the same sample for reproducibility. The measured XPS data were analyzed using PHI Multipak software (V9.5.0.8). The porous and non-homogeneous nature of the samples at the microscopic scale, in addition to poor conductivity (discussed in the next paragraph), prevents extracting any meaningful quantitative information. Hence, XPS results in this paper should be considered as qualitative in nature.

The thick oxides are poorly conductive and, as a consequence, undergo considerable charging during measurements. Two strategies were applied in order to overcome this problem: using an electron gun to saturate the surface with electrons during measurements (used on samples prepared at 3,15 and $23 \mathrm{~V}$ ) or using a molybdenum mask (used on $30 \mathrm{~V}$ sample).

\subsection{3. $X$-ray diffraction (XRD)}

XRD data were acquired using Rigaku MiniFlexII instrument equipped with Cu-tube as radiation source. Diffraction patterns were collected in the Bragg-Brentano $\theta-2 \theta$ configuration for all the samples in the $2 \theta$ range from $20^{\circ}$ to $100^{\circ}$ with a step of $0.02^{\circ}$.

\subsubsection{Raman spectroscopy}

Raman spectra were acquired using the WITec alpha300R confocal Raman microscope with $532 \mathrm{~nm}$ laser with $600 \mathrm{~g} / \mathrm{mm}$ grating. Laser intensity at the sample was $\sim 54 \mathrm{~mW}$ and $\times 20$ objective. The single-point spectrum was collected with an integration time of $0.1 \mathrm{~s}$.

\section{Results and discussion}

\subsection{Electrochemistry of copper anodization in $\mathrm{Na}_{2} \mathrm{CO}_{3}$}

As mentioned in the experimental part, linear sweep voltammetry (LSV) was performed to determine the applied voltage range for copper anodizing. It is apparent from Fig. 1 that there are certain stages in the curve that are analogous to aluminum LSV. Up to $30 \mathrm{~V}$, the recorded current densities are low, not exceeding $0.1 \mathrm{~A} / \mathrm{cm}^{2}$. Thus, by analogy to aluminum anodizing, it can be considered that at this range ion migration controls the process, resulting in uniformity of the grown nanostructures [32]. For aluminum, the analogous voltage range is considered the mild anodization range [32]. From 31 to $45 \mathrm{~V}$, a rapid current density increase with the voltage is noticeable (Fig. 1). It can be attributed to the mixed kinetics of the anodic oxide growth [31], however simultaneously a gas generation at the anode was observed. From $45 \mathrm{~V}$ to $60 \mathrm{~V}$, one can observe a plateau with the current density at the level of $0.5 \mathrm{~A} / \mathrm{cm}^{2}$. This range of voltage is supposed to provide a mechanism of anodization in which ion diffusion is key (anions from the bulk of the electrolyte migrate to the pore bottoms - electrolyte interface and simultaneous ejection of the cations towards the electrolyte bulk, when growth of alumina is considered) [32]. Considering analogies between copper and aluminum anodizing, one can conclude that this range is a suitable regime for copper hard anodizing [30,32]. Above $60 \mathrm{~V}$, there is the largest current density increase, resulting in the violent gas generation and simultaneous copper anode decomposition. Copper is consumed so fast, that the sample is being destroyed. This can be observed from the dramatic current density decrease above $85 \mathrm{~V}$ (current density was calculated by referring to the initial surface area of the sample). Moreover, electrolyte turns rapidly blue, indicating the release of a large quantity of $\mathrm{Cu}^{2+}$ cations.

Nanostructures formed by copper anodizing have unique morphology. According to previous research, nanoneedles are formed by copper anodizing [17], whereas anodization of other metals (e.g., Al, Ti) results in the formation of hexagonally arranged nanopores and nanotubes. Surprisingly, recorded current density vs. time curves for copper anodizing are similar to the ones reported for aluminum anodizing, as 

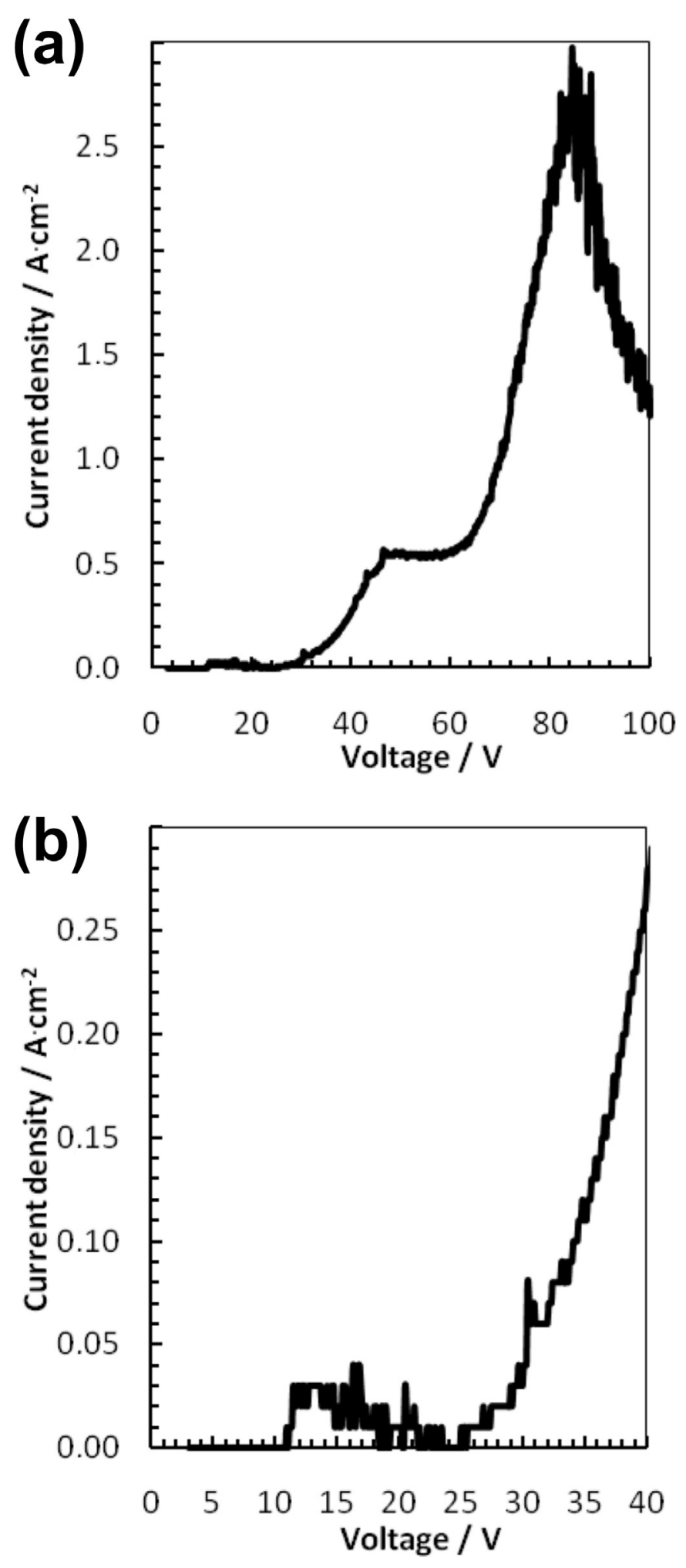

Fig. 1. Linear sweep voltammograms of copper in $0.1 \mathrm{M} \mathrm{Na}_{2} \mathrm{CO}_{3}$ in the range of 0-100 V (a) and 0-40 V (b).

shown in Figs. 2 and 3 [33], revealing that anodization of copper also occurs according to the adsorption-nucleation mechanism, despite the different morphology of the grown oxide. Nevertheless, due to the presence of two oxidation states of copper involved, the mechanism of the phenomenon is more complex for copper anodizing than in case of aluminum anodizing. Firstly, a rapid decrease in current density is

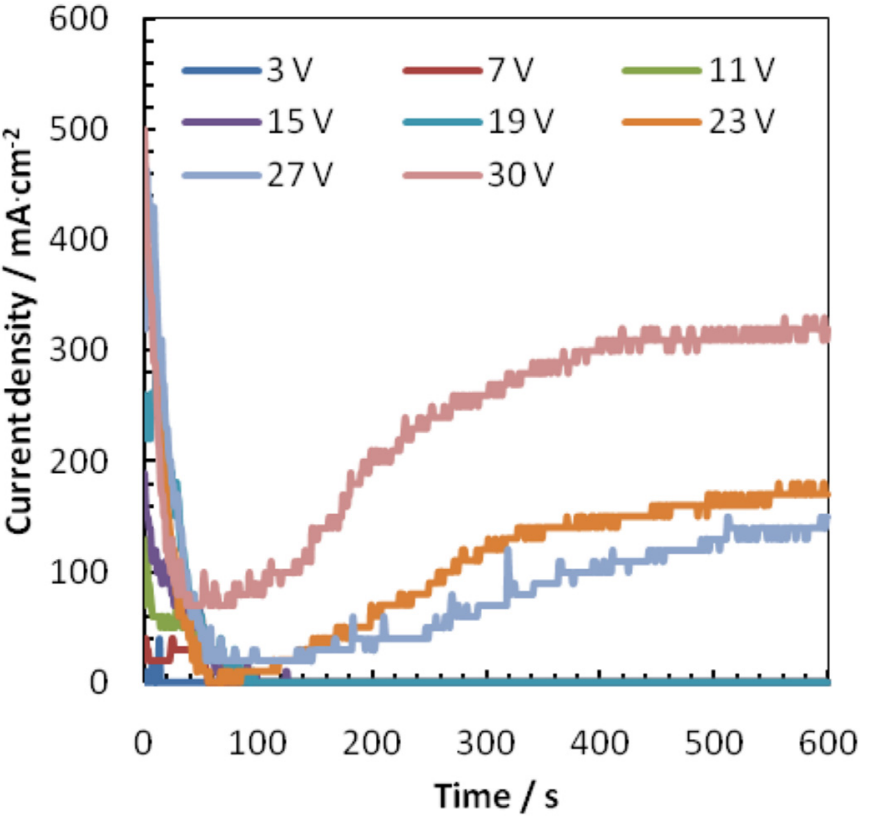

Fig. 2. Current density transients registered during copper anodization in $0.1 \mathrm{M}$ $\mathrm{Na}_{2} \mathrm{CO}_{3}$ at various voltages.

observed within the first $60 \mathrm{~s}$ (Fig. $3 \mathrm{~b}$ ). This behavior is generally linked to the adsorption of anions on the surface and formation of $\mathrm{CuOH}$ and $\mathrm{Cu}_{2} \mathrm{O}$, serving as a barrier layer $[17,34,35]$ (Eqs. (1) and (2)):

$\mathrm{Cu}+\mathrm{OH}-\rightarrow \mathrm{CuOH}+\mathrm{e}$

$2 \mathrm{CuOH} \rightarrow \mathrm{Cu} 2 \mathrm{O}+\mathrm{H} 2 \mathrm{O}$

Simultaneously, the freshly grown $\mathrm{CuOH}$ or $\mathrm{Cu}_{2} \mathrm{O}$ may undergo secondary reaction with the $\mathrm{OH}^{-}$anions and form water-soluble coordination anions (Eqs. (3) and (4)):

$2 \mathrm{CuOH}+\mathrm{OH}-\rightarrow \mathrm{Cu} 2 \mathrm{O} 2 \mathrm{H}-+\mathrm{H} 2 \mathrm{O}$

$\mathrm{Cu} 2 \mathrm{O}+2 \mathrm{OH}-\rightarrow \mathrm{Cu} 2 \mathrm{O} 22-+\mathrm{H} 2 \mathrm{O}$

These secondary reactions allow to form small cracks and voids in the barrier layer and, consequently, stop the current density decrease in time by enabling efficient charge transfer between the electrolyte and the anode [33]. Further development of those easy-paths is seen for both aluminum and copper anodizing, as current density increases with time, i.e. from about 80 to $800 \mathrm{~s}$ for copper anodizing and $20-120 \mathrm{~s}$ for $\mathrm{Al}$ anodizing, respectively (see Fig. 3b).

In the case of aluminum, the produced oxide $\mathrm{Al}_{2} \mathrm{O}_{3}$ is an insulator, causing high electric resistance of the grown oxide, which hinders charge transfer through the pores' walls. As a result, further reactions take place only at the pore bottoms and current density then becomes stable in time (formation of AAO in sulfuric acid at $20 \mathrm{~V}$ [36], resulting in the typically hexagonal pore structures of AAO's).

However, in the case of copper anodizing, the formed oxide $\mathrm{Cu}_{2} \mathrm{O}$ is a semiconductor that can be easily oxidized to $\mathrm{CuO}$ (Eq. (5)) [17,34]:

$\mathrm{Cu} 2 \mathrm{O}+2 \mathrm{OH}-+\mathrm{H} 2 \mathrm{O} \rightarrow 2 \mathrm{Cu}(\mathrm{OH}) 2+2 \mathrm{e}$

At the same time, metallic copper can be oxidized to $\mathrm{Cu}(\mathrm{OH})_{2}$ or $\mathrm{CuO}$ (Eqs. (6) and (7)) [17,33]:

$\mathrm{Cu}+2 \mathrm{OH}-\rightarrow \mathrm{Cu}(\mathrm{OH}) 2+2 \mathrm{e}$

$\mathrm{Cu}+2 \mathrm{OH}-\rightarrow \mathrm{CuO}+\mathrm{H} 2 \mathrm{O}+2 \mathrm{e}$

And also water-soluble $\mathrm{Cu}(\mathrm{OH})_{4}^{-}$with copper at $\mathrm{Cu}^{3+}$ oxidation state can be formed from $\mathrm{Cu}^{2+}$ species (Eqs. (8) and (9)): 

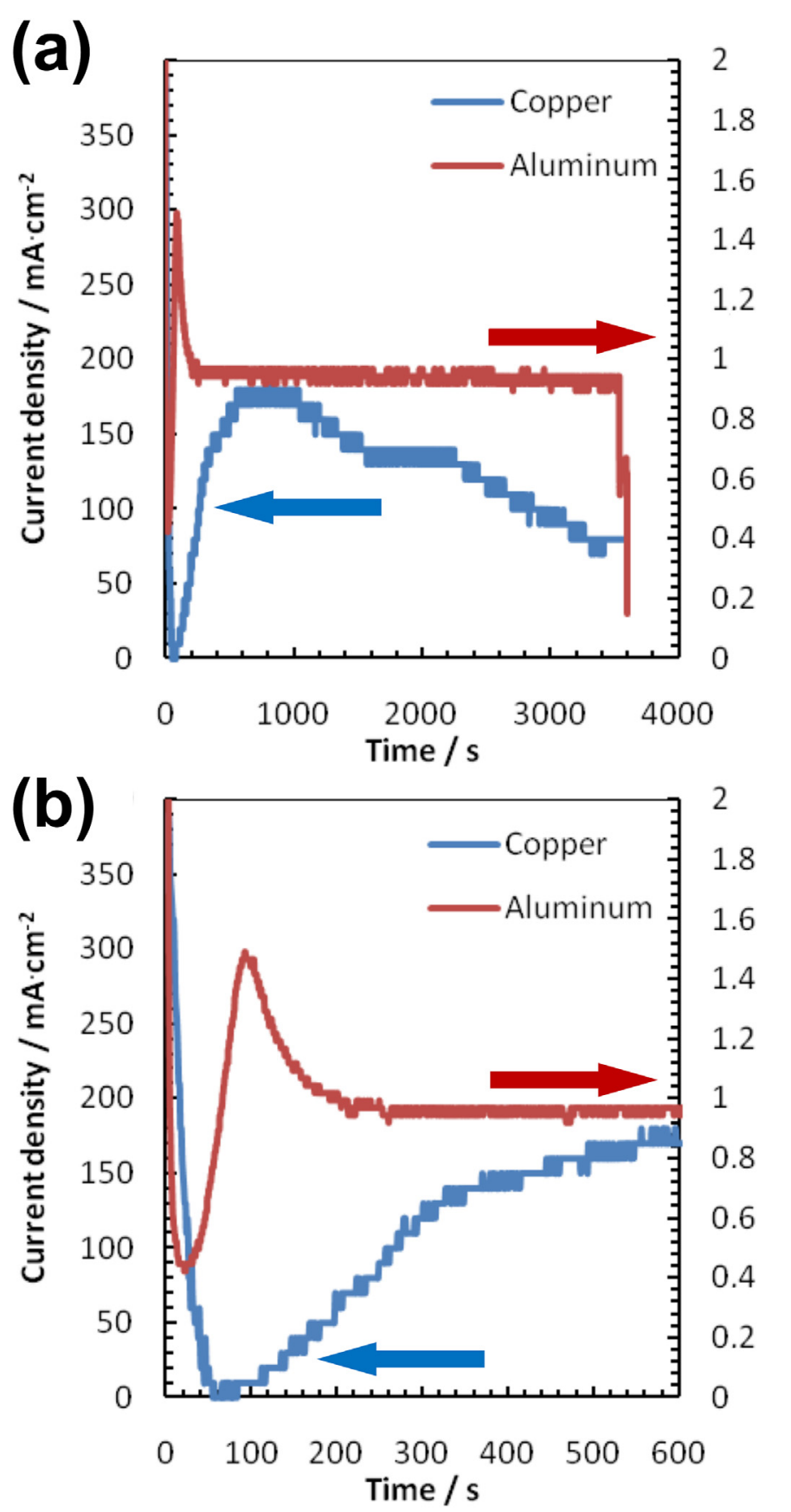

Fig. 3. Current density transients of copper anodizing in $0.1 \mathrm{M} \mathrm{Na}_{2} \mathrm{CO}_{3}$ vs. current density of aluminum anodizing in $20 \mathrm{wt} \% \mathrm{H}_{2} \mathrm{SO}_{4}$ at $20 \mathrm{~V}$ [36]: (a) $0-4000 \mathrm{~s}$ and (b) 0-600 s.

$\mathrm{CuOH} 2+2 \mathrm{OH}-\rightarrow \mathrm{Cu}(\mathrm{OH}) 4-+\mathrm{e}$

$\mathrm{CuO}+\mathrm{H} 2 \mathrm{O}+2 \mathrm{OH}-\rightarrow \mathrm{Cu}(\mathrm{OH}) 4-+\mathrm{e}$

Hence, $\mathrm{Cu}^{+}$species building up the growing oxide may simultaneously be oxidized to $\mathrm{Cu}^{2+}$ species. As a result, copper reaction may occur at the formed easy-paths, but also on the surface of the formed oxide. Moreover, the gradual current density decrease in time (Fig. 3) can be interpreted as follows: reactions are occurring inter alia on the surface of the grown oxide, thus with time, the oxide is thicker and charge has a longer path to go through the formed semiconductor, which decreases the total current density. Additionally, the longer the reaction takes place, the more $\mathrm{Cu}^{+}$gets oxidized into $\mathrm{Cu}^{2+}$ and the less reaction sites

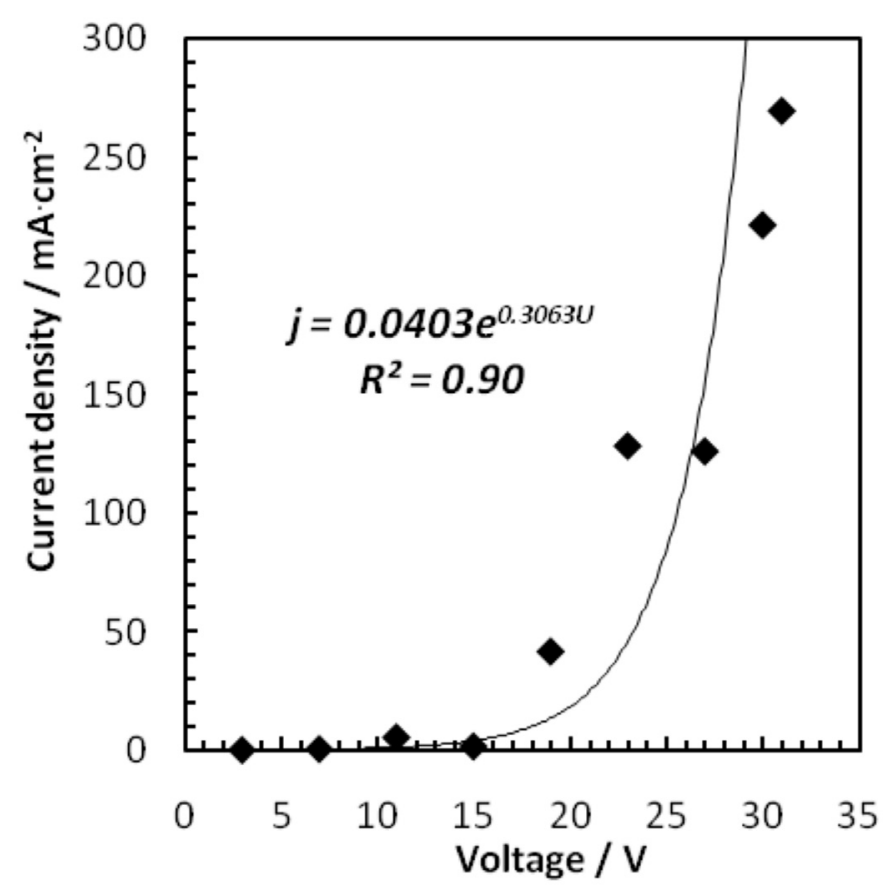

Fig. 4. Average current density recorded during copper anodizing in $0.1 \mathrm{M}$ $\mathrm{Na}_{2} \mathrm{CO}_{3}$ vs. voltage.

will be available on the surface of the grown oxides. Similar current density behavior has been observed for the higher values of applied voltage, i.e. 23-30 V (Fig. 2).

Fig. 4 shows the average current density of the steady state growth of anodic film (since plateau is achieved in the current density transient, for example from $500 \mathrm{~s}$ time in Fig. 2) as a function of anodizing voltage. In the case of copper anodizing in $0.1 \mathrm{M} \mathrm{Na}_{2} \mathrm{CO}_{3}$, the current density increases exponentially with voltage, exhibiting the same trend found in aluminum anodization $[37,38]$. The current density for anodization of $\mathrm{Al}$ in aqueous solution of sulfuric acid is up to $55 \mathrm{~mA} / \mathrm{cm}^{2}$ [38], while anodizing in oxalic acid can reach up to $100 \mathrm{~mA} / \mathrm{cm}^{2}$ [37]. In the case of copper anodizing in $\mathrm{Na}_{2} \mathrm{CO}_{3}$, recorded average current densities are up to $220 \mathrm{~mA} / \mathrm{cm}^{2}$ (Fig. 4). These higher current densities are also related to the fact that anodic alumina is an insulator, whereas grown cuprous and cupric oxides are semiconductors.

\subsection{Morphology of grown oxide nanostructures}

As-obtained samples after anodizing in $0.1 \mathrm{M} \mathrm{Na}_{2} \mathrm{CO}_{3}$ were rough, brittle and parts of the grown product could easily delaminate. Independently from the anodizing voltage, all surfaces were made up of small, randomly distributed blue and black regions, indicating the presence of $\mathrm{Cu}(\mathrm{OH})_{2}$ and $\mathrm{CuO}$, respectively.

SEM images revealed that for the two lowest voltages ( $3 \mathrm{~V}$ and $7 \mathrm{~V}$, resp.), the grown oxides were just barrier-type ones (Fig. 5). However, those barrier type oxides are made of (sub)micron-sized spheres and in the case of $7 \mathrm{~V}$ (Fig. 5b), the surface porosity and number density of the spherical features are higher than for $3 \mathrm{~V}$ (Fig. 5a), showing faster evolution of the oxide at higher voltage.

For even higher voltages, the formation of nanostructures is observed (Fig. 6): in the range of 11-23 V the formed structures are nanowires-like, but chaotically organized (a-d). At $27 \mathrm{~V}$ and $30 \mathrm{~V}$, the grown oxide is in the form of (thicker) vertically aligned nanorods. Generally, passivation, or anodization of copper, produces oxides in the form of nanoneedles, thus with sharp tips and diameter of the structures decreasing with their length [17]. Here, in the case of the nanostructures formed at 27 and $30 \mathrm{~V}$ a distinct plane is visible at the tips of the nanostructures, thus showing a well-ordered crystallinity of the formed oxide. As mentioned in section 


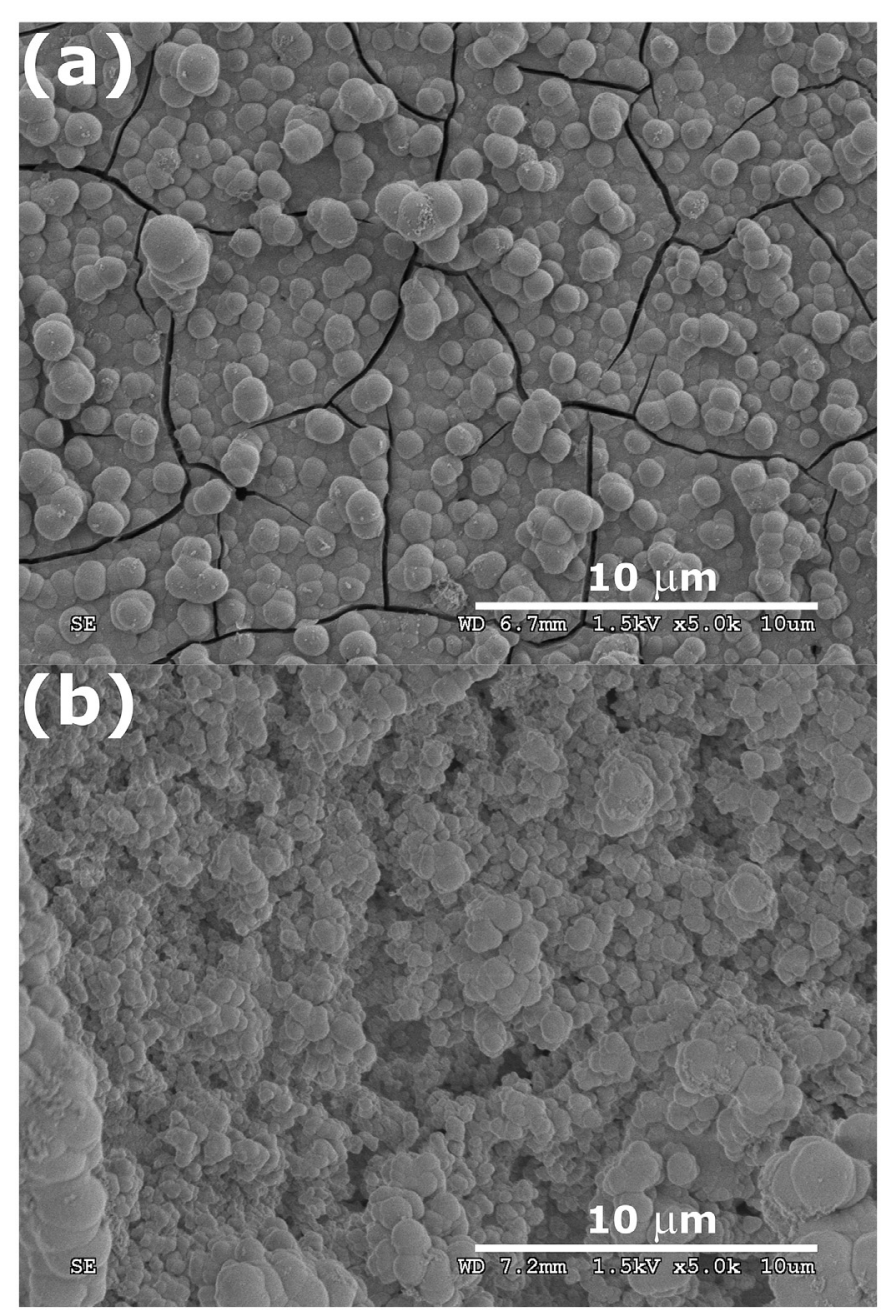

Fig. 5. FE-SEM images of barrier type oxides formed by copper anodizing in $0.1 \mathrm{M} \mathrm{Na}_{2} \mathrm{CO}_{3}$ at 3 (a) and $7 \mathrm{~V}$ (b).

3.1, the current density transient recorded for $31 \mathrm{~V}$ was a high-amplitude noise, accompanied by the rapid oxygen evolution at the anode, thus formation of nanostructured anodic oxide could not be expected at this operating condition. Nevertheless, microscopic observation of the sample surface shows well-established, facetted, nanorods (Fig. 7). It is,

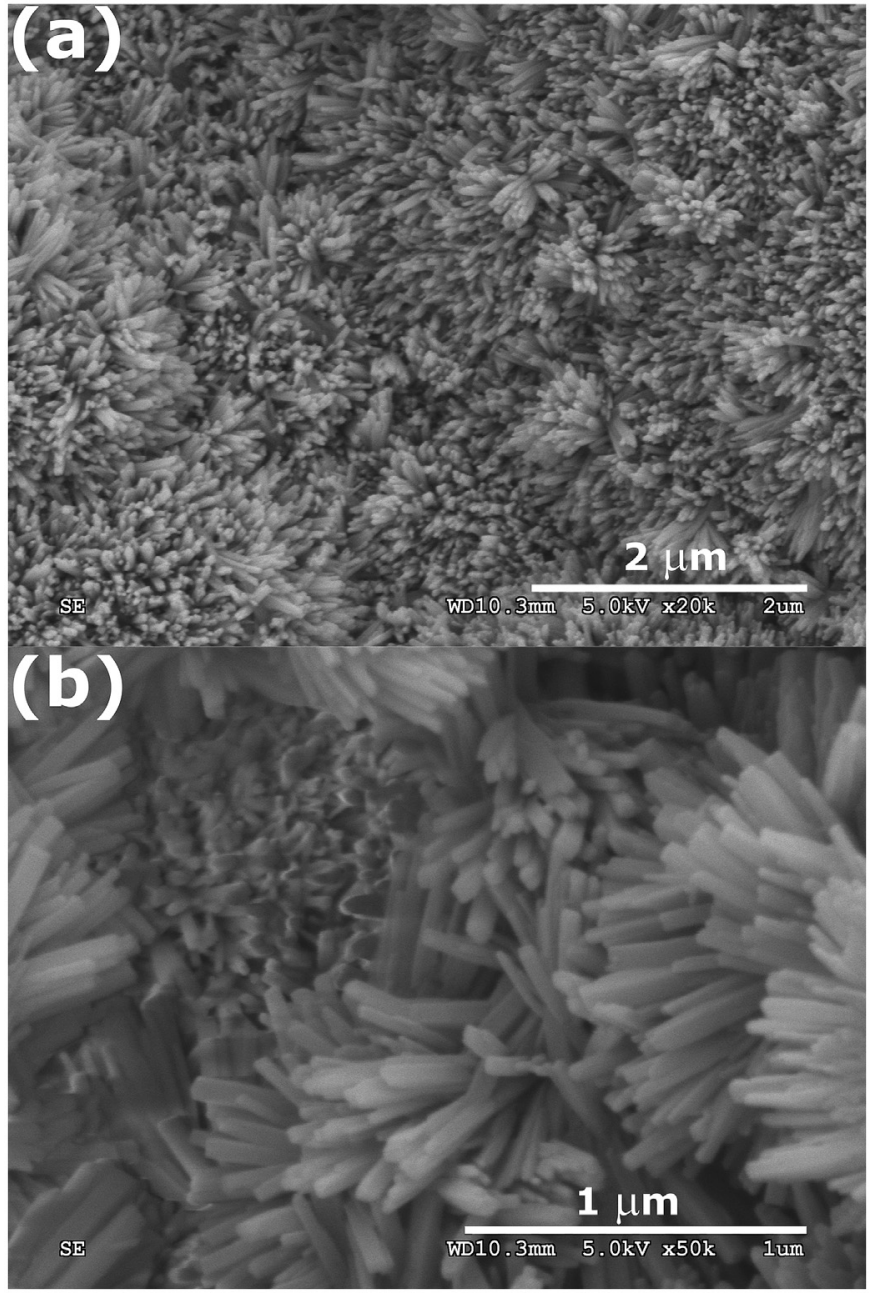

Fig. 7. FE-SEM images of nanostructures formed by copper anodizing in $0.1 \mathrm{M}$ $\mathrm{Na}_{2} \mathrm{CO}_{3}$ at $31 \mathrm{~V}$ (various magnifications).

however, also apparent that some regions were selectively etched-out (Fig. 7b).

Quantitative image analysis reveals that the smallest diameter of the nanorods was $28 \pm 9 \mathrm{~nm}$ (15 V), while the greatest diameter was found to be $109 \pm 15 \mathrm{~nm}(30 \mathrm{~V})$. Diameter of the nanorods was found to roughly
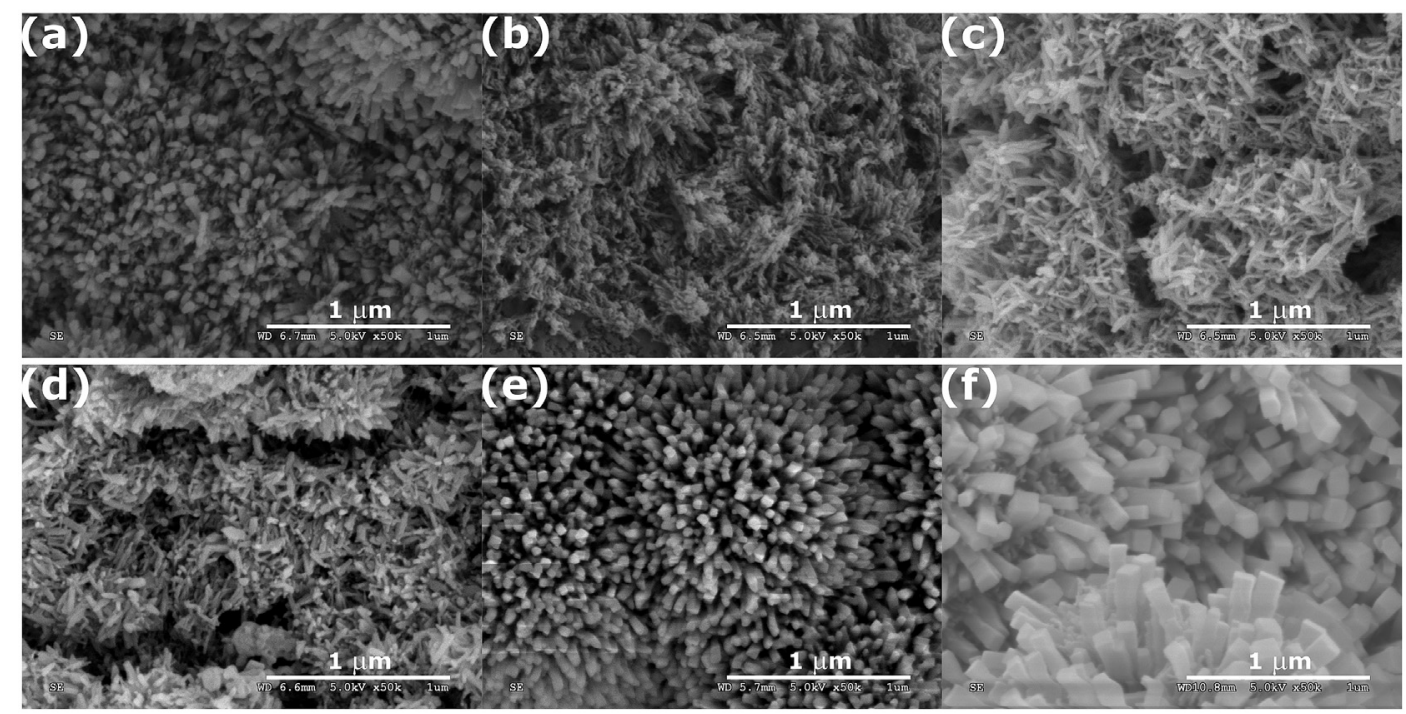

Fig. 6. FE-SEM images of nanorods formed by copper anodizing in $0.1 \mathrm{M} \mathrm{Na}_{2} \mathrm{CO}_{3}$ at $11 \mathrm{~V}$ (a), $15 \mathrm{~V}$ (b), $19 \mathrm{~V}$ (c), $23 \mathrm{~V}$ (d), $27 \mathrm{~V}$ (e) and $30 \mathrm{~V}$ (f). 


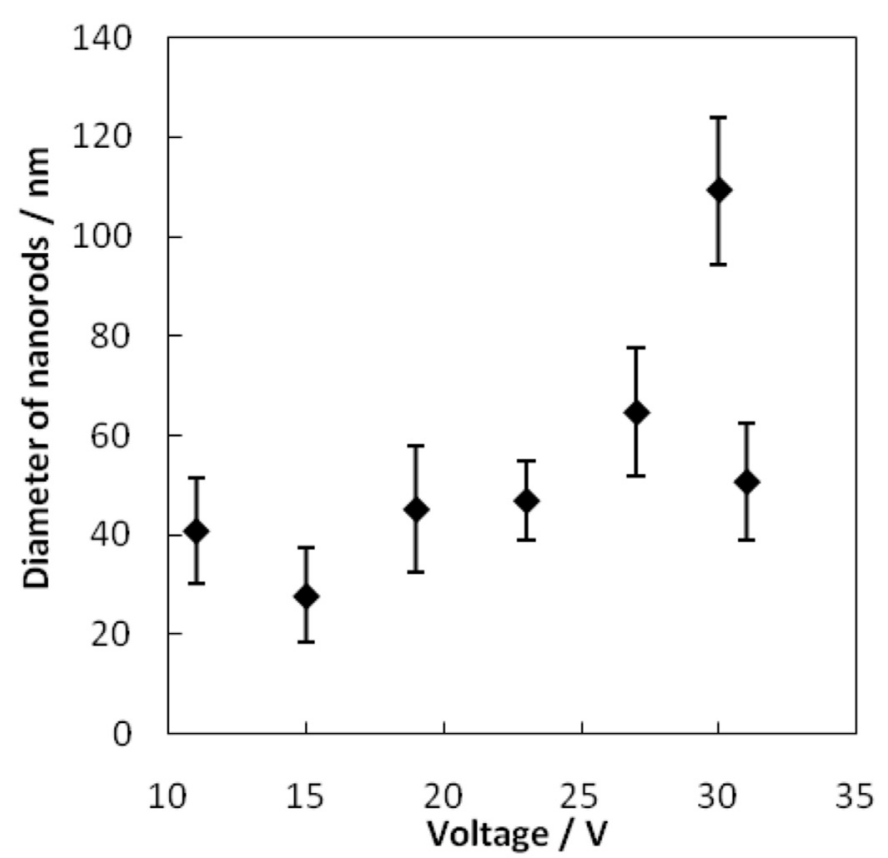

Fig. 8. Diameter of the obtained nanorods vs. anodizing voltage.

increase with the voltage up to $30 \mathrm{~V}$ (Fig. 8). Anodization at $31 \mathrm{~V}$ resulted in the formation of much smaller nanorods $(51 \pm 12 \mathrm{~nm}$ in diameter), which was probably caused by violent phenomena linked to aggressive gas formation, and strong attraction of $\mathrm{OH}^{-}$anions on the surface of the electrode, contributing in secondary field-assisted dissolution of the grown oxide (see Eqs. (8) and (9)).

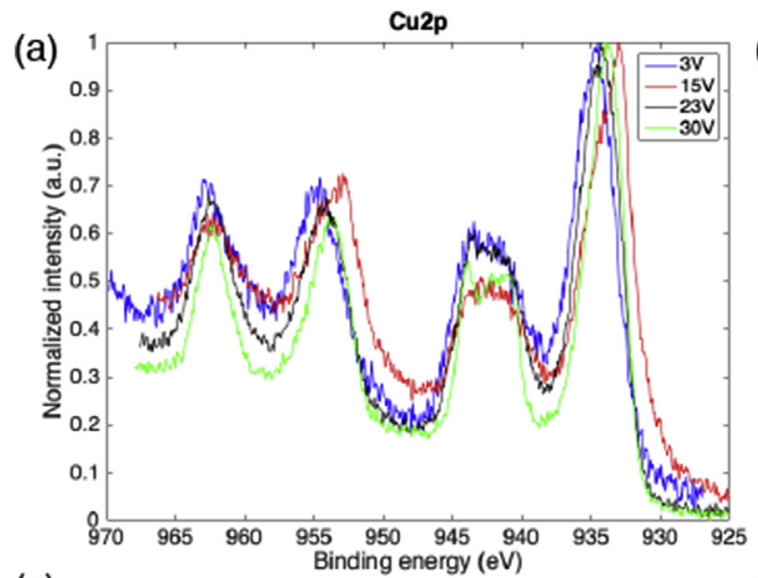

(c)

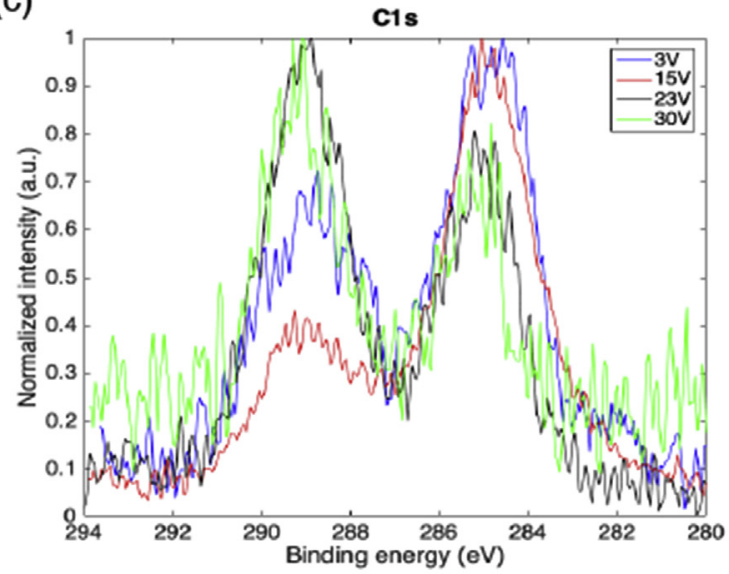

\subsection{Chemical and phase composition of the anodized copper samples}

\subsubsection{XPS analysis}

The main elements detected on all the anodized sample surfaces were copper and oxygen, with minor quantities of carbon. All specimens had elemental composition, ranging between 13 and 39 at.\% Cu, 51-65 at.\% $\mathrm{O}$ and 8-34 at.\% C (with the different levels of atmospheric contamination causing large variations in the relative percentages). Some minor contaminates, including $\mathrm{Na}, \mathrm{Ca}, \mathrm{S}$ and $\mathrm{Ni}$, were found in some specimens. Fig. SI 1 shows an example of the XPS survey recorded from the sample anodized at $15 \mathrm{~V}$.

To acquire information about the surface state, XPS analysis at grazing angle $\left(15^{\circ}\right)$ was conducted. The two main $\mathrm{Cu}$ peaks in the spectra, Cu2p and the Auger line Cu LMM, were recorded at highresolution, as well as the $\mathrm{O} 1 \mathrm{~s}$ and $\mathrm{C} 1 \mathrm{~s}$ peaks. To assure the correct assignment of the binding energy position, each spectrum was shifted using the adventitious hydrocarbon component of $\mathrm{C} 1 \mathrm{~s}$ to $284.8 \mathrm{eV}$ as a standard reference. As shown in Fig. 9, the four samples (after anodization at $3 \mathrm{~V}, 15 \mathrm{~V}, 23 \mathrm{~V}$, and $30 \mathrm{~V}$, resp.) display similar Cu2p and Cu LMM spectra (Fig. 9 (a) and (b)). The Cu2p peak is composed of a doublet peak $\left(\mathrm{Cu} 2 \mathrm{p}_{3 / 2}\right.$ and $\mathrm{Cu} 2 \mathrm{p}_{1 / 2}$ ) due to spin-orbit splitting. Cu2p consists of two main components with the envelope maxima located at 934 and $954 \mathrm{eV}$. The two peaks exhibit strong satellite peaks approx. $10 \mathrm{eV}$ higher than the main peaks. These satellites are caused by multiple excitations in copper oxides and they are known characteristics of $\mathrm{Cu}^{2+}(\mathrm{CuO}$, $\left.\mathrm{Cu}(\mathrm{OH})_{2}\right)[39]$.

The Cu LMM Auger lines were also recorded (Fig. 9b). For 3, 15 and $23 \mathrm{~V}$, they are within the range of $570.2 \pm 0.4 \mathrm{eV}$ corresponding to $\mathrm{Cu}_{2} \mathrm{O}$, while the peak recorded for the $30 \mathrm{~V}$ sample at $569.2 \mathrm{eV}$ is characteristic to $\mathrm{CuO}$. This indicates that copper anodization leads to the formation of $\mathrm{CuO}, \mathrm{Cu}(\mathrm{OH})_{2}$ and/or $\mathrm{Cu}_{2} \mathrm{O}$, or a mixture thereof.

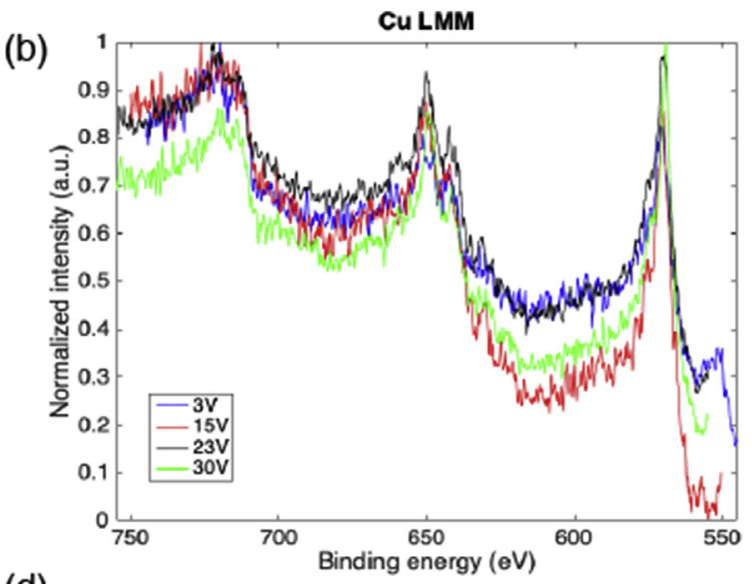

(d)

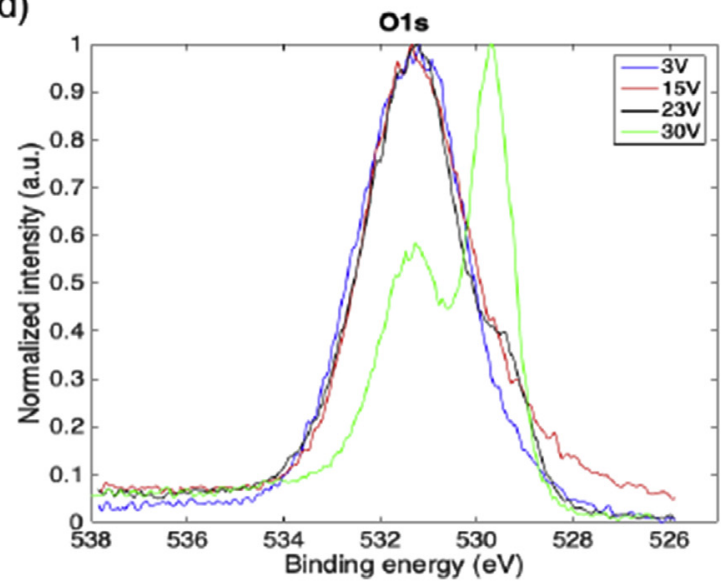

Fig. 9. X-ray photoelectron spectra of copper samples anodizing at 3, 15, 23 and $30 \mathrm{~V}$ in Cu2p binding energy range (a), Cu LMM (b), O1s (c) and C1s (d). 
The O1s HRES peaks (Fig. 9c) may provide superior distinction between the different samples. For the $3 \mathrm{~V}$ sample, the oxygen 01 s peak is wide and symmetric. In case of the samples anodized at higher voltages of $15 \mathrm{~V}$ and $23 \mathrm{~V}$, a shoulder at the lower binding energy side appears, while the main component is similar to the one at $3 \mathrm{~V}$. After anodizing at $30 \mathrm{~V}$, however, the O1s peak exhibits two sharp maxima and the ratio between the two components changes, with the main component at lower binding energy. This change from a wide Gaussian peak to a sharp feature is consistent with SEM observations for a transition from a compact film produced at lower anodizing voltage to well-developed, crystalline nanostructures obtained at greater voltages, like at $30 \mathrm{~V}$.

The different $01 \mathrm{~s}$ core levels were fitted into three components centered at $529.6 \mathrm{eV}, 531.1 \mathrm{eV}$ and $532.3 \mathrm{eV}( \pm 0.4 \mathrm{eV})$, as can be seen in Fig. 10. The calculated relative peak areas are listed in Table 1 . The first component corresponds well with the binding energy of lattice oxygen in $\mathrm{CuO}\left(\mathrm{O}^{2-}\right)[40,41]$. The relative share of this component (O1 in Table 1) increases progressively with the anodizing voltage, indicating an increase in the $\mathrm{CuO}$ fraction in the samples. The second component, $\mathrm{O} 2$ in Table 1 , has been previously assigned to hydroxides as in $\mathrm{Cu}(\mathrm{OH})_{2}[40$, 41] and superstoichiometric oxygen [42]. From the peak shape and binding energy of Cu2p, it is more likely that the peak in here is $\mathrm{Cu}(\mathrm{OH})_{2}$. In addition, component $\mathrm{O} 2$ contains a minor contribution from $\mathrm{CO}$. The third component, $\mathrm{O} 3$, at the highest binding energy is oxygen in adsorbed $\mathrm{H}_{2} \mathrm{O}$ and $\mathrm{CO}_{2}$. Peak deconvolution of the carbon envelope (Fig. 9d) into three components centered at $284.8 \mathrm{eV}, 286.3 .4 \mathrm{eV}$ and $289.3 \mathrm{eV}$ reveals the presence of $\mathrm{C}-\mathrm{C} / \mathrm{C}-\mathrm{H}, \mathrm{CO}$ and $\mathrm{CO}_{2}$ bonds, respectively. A relative higher percentage $(<50 \%)$ of carbonate $\mathrm{CO}_{2}$ component was found at higher potentials, probably due to a greater amount of incorporated carbonate ions during anodizing.
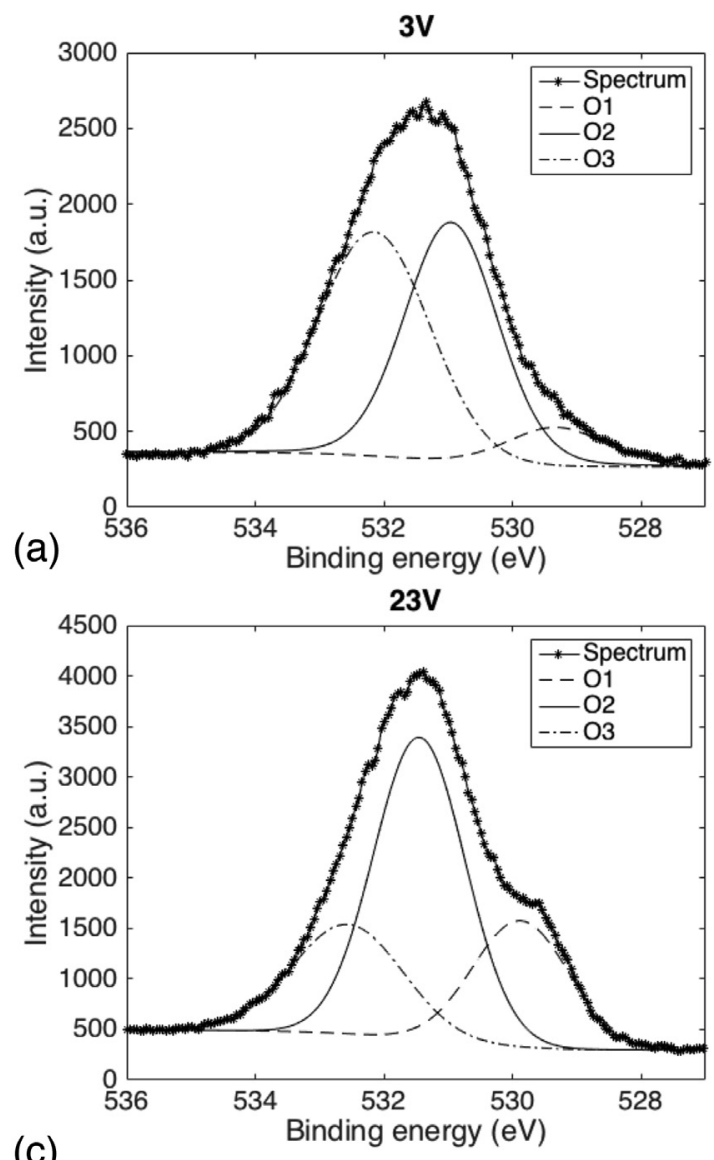

Table 1

Relative deconvoluted peak area (in \%) of the subcomponents in C1s and O1s as calculated from peak fitting of the four different samples.

\begin{tabular}{|c|c|c|c|c|c|c|}
\hline \multirow[t]{2}{*}{ Voltage } & \multicolumn{3}{|l|}{ C1s } & \multicolumn{3}{|l|}{ 01s } \\
\hline & $\begin{array}{l}\text { C1 } \\
\text { (area } \\
\% \text { ) }\end{array}$ & $\begin{array}{l}\text { C2 } \\
\text { (area } \\
\% \text { ) }\end{array}$ & $\begin{array}{l}\text { C3 } \\
\text { (area } \\
\% \text { ) }\end{array}$ & $\begin{array}{l}\text { O1 } \\
\text { (area } \\
\% \text { ) }\end{array}$ & $\begin{array}{l}\text { O2 } \\
\text { (area } \\
\% \text { ) }\end{array}$ & $\begin{array}{l}\text { O3 } \\
\text { (area } \\
\% \text { ) }\end{array}$ \\
\hline $3 \mathrm{~V}$ & 33 & 30 & 37 & 8 & 45 & 48 \\
\hline $15 \mathrm{~V}$ & 48 & 24 & 28 & 10 & 23 & 67 \\
\hline $23 \mathrm{~V}$ & 27 & 18 & 55 & 24 & 53 & 23 \\
\hline $30 \mathrm{~V}$ & 26 & 21 & 53 & 51 & 42 & 7 \\
\hline
\end{tabular}

\subsection{2. $X$-ray diffraction}

X-ray diffraction analysis reveals that the majority of copper anodizing products is crystalline. All the anodic oxides in as-obtained form, like alumina [43] or titania [44], are amorphous, except anodic zirconia [45]. Thus, this is one of the major differences between anodically grown nanostructures on copper and other anodic oxides. In all the samples investigated in this study, reflections from cuprite $\left(\mathrm{Cu}_{2} \mathrm{O}\right)$ and tenorite $(\mathrm{CuO})$ were distinct, showing without any doubts a presence of both oxides (Fig. 11). Presence of cuprite was indicated by reflections from three planes: (110), (111) and (200), with (110) showing the greatest intensity. Presence of tenorite was confirmed by one, but very intensive, reflection from the (002) plane. It means that $\mathrm{CuO}$ grows in a preferred direction. The data are coherent with the information acquired from the XPS data: in the whole voltage range, except $3 \mathrm{~V}$, both oxides are present (see Fig. 12).

Furthermore, when the tenorite (002) reflection intensity is compared to the intensity of the most intensive reflection of cuprite (110), an increase in the relative amount of tenorite is observed, especially apparent
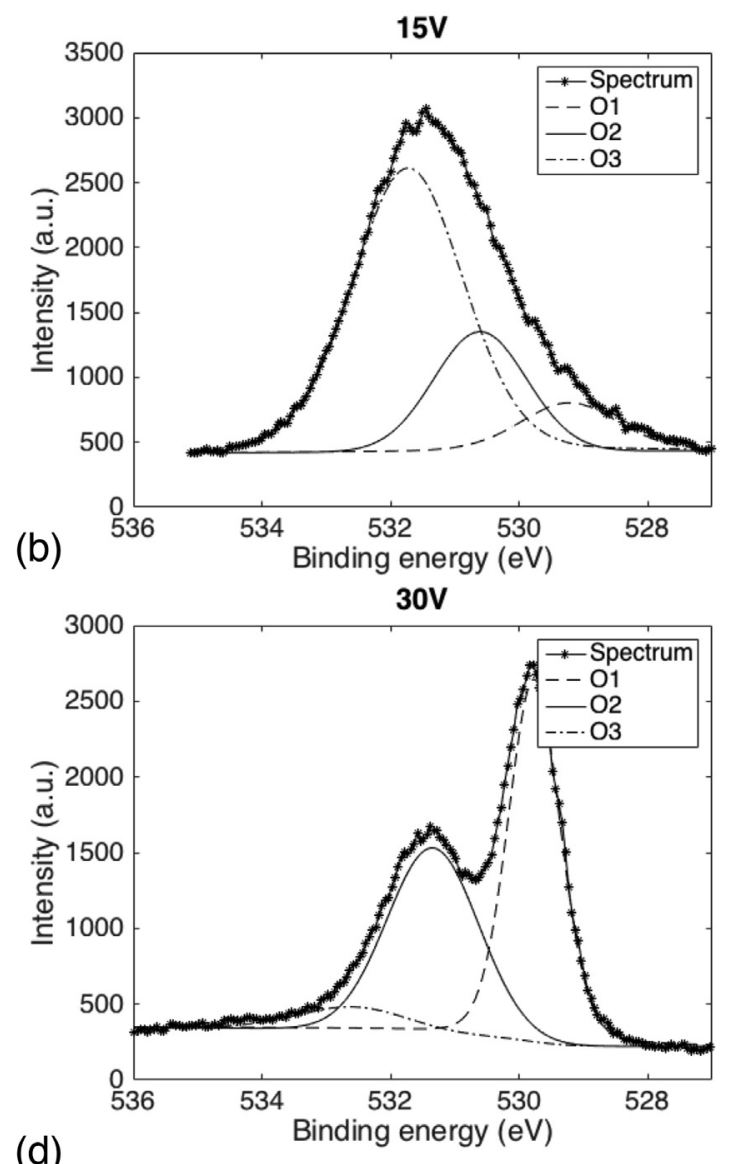

(d)

Fig. 10. Deconvoluted peaks for 01 s binding energy range for copper samples anodized at $3 \mathrm{~V}$ (a), $15 \mathrm{~V}$ (b), $23 \mathrm{~V}$ (c) and $30 \mathrm{~V}$ (d). 


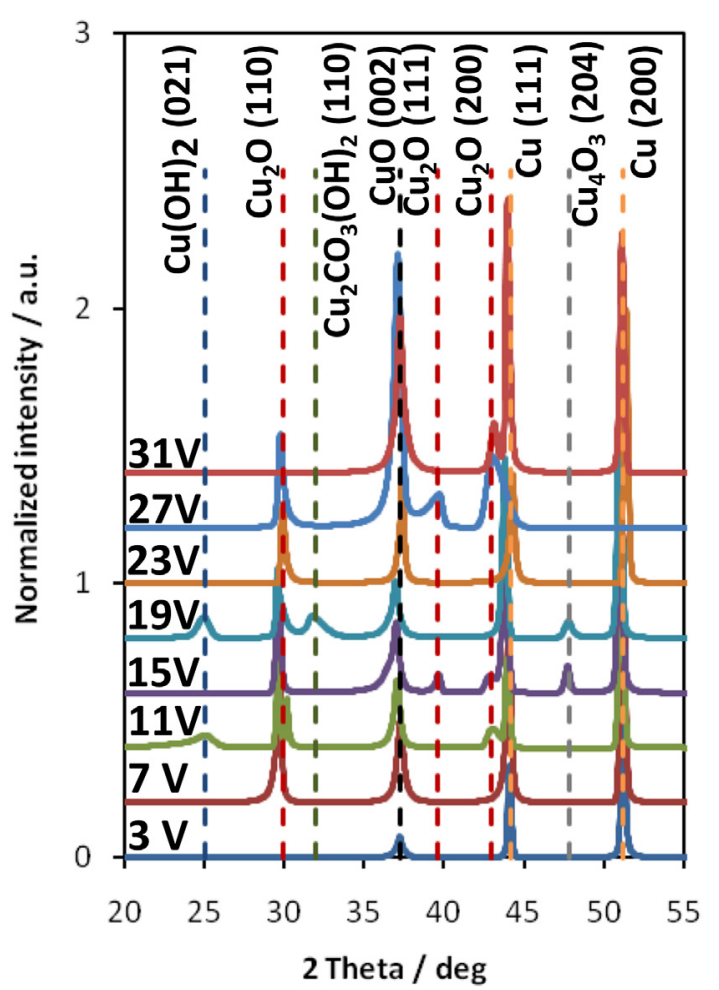

Fig. 11. X-ray diffraction patterns of copper samples anodized in $0.1 \mathrm{M} \mathrm{Na}_{2} \mathrm{CO}_{3}$.

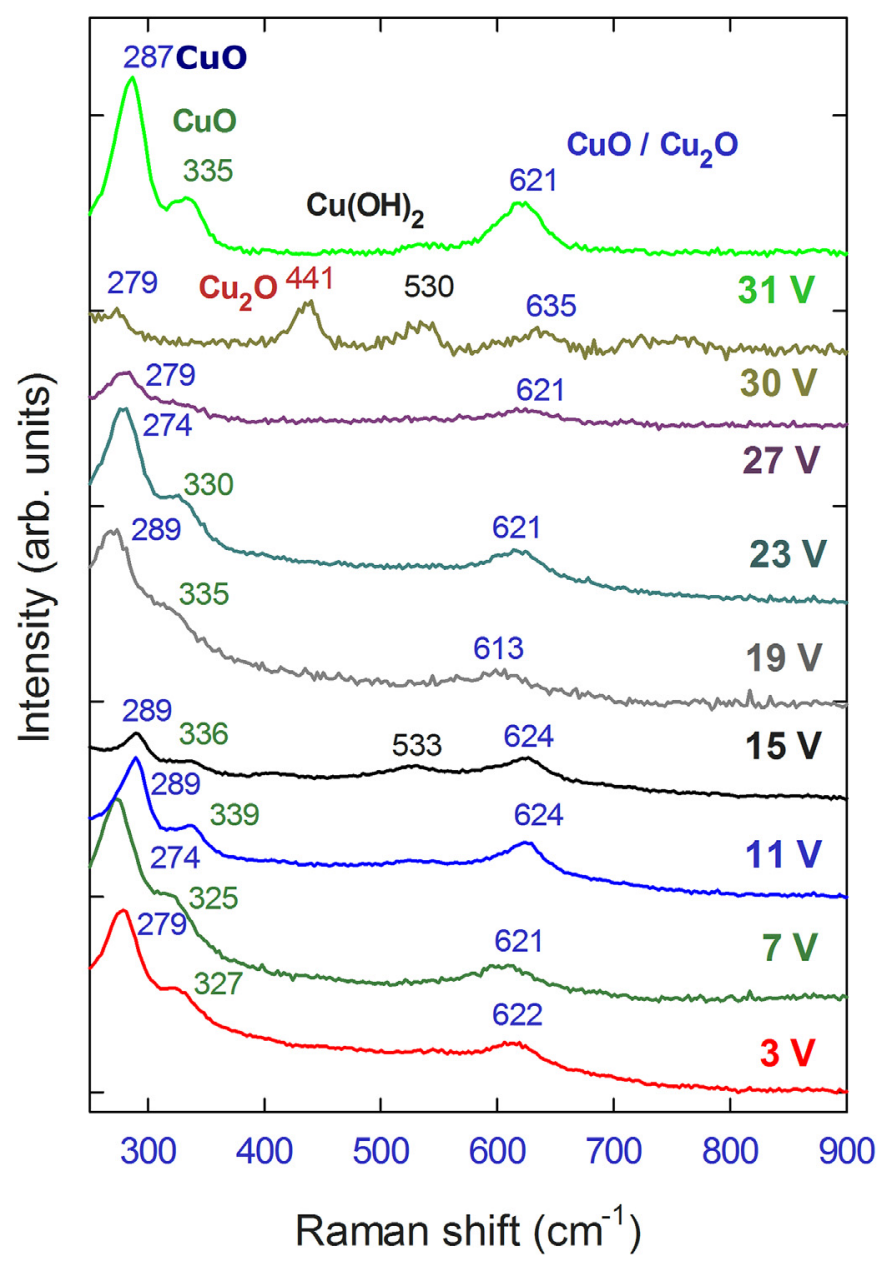

Fig. 12. Raman spectra recorded on copper samples anodized in $0.1 \mathrm{M} \mathrm{Na}_{2} \mathrm{CO}_{3}$. for the sample anodized at $27 \mathrm{~V}$ (Fig. SI 2). At $31 \mathrm{~V}$, the cuprite (110) reflection even disappears. This means that the greater the voltage, the easier the oxidation of copper to $\mathrm{Cu}^{2+}$ species.

In some individual cases of intermediate voltage (i.e., $15 \mathrm{~V}$ and $19 \mathrm{~V}$ ), also mixed oxide, paramelconite, $\mathrm{Cu}_{4} \mathrm{O}_{3}$ reflection from the (204) plane was measured.

$\mathrm{Cu}(\mathrm{OH})_{2}$ was found by XPS in significant amounts in samples formed at both low and high voltages. XRD patterns reveal only in two cases low intensity reflections from the $\mathrm{Cu}(\mathrm{OH})_{2}(021)$ plane. It means that, although the formed oxides are crystalline, anodically grown $\mathrm{Cu}(\mathrm{OH})_{2}$ is rather amorphous. Moreover, when compared to XRD, XPS has significantly lower penetration depth (up to $5-10 \mathrm{~nm}$ ), allowing for a high surface sensitivity. Thus, up to $53 \%$ of the oxygen species in the form of $\mathrm{Cu}(\mathrm{OH})_{2}$ in the examined samples reveals that the hydroxide forms the outer layer of the grown nanorods. This is consistent with the mechanism proposed by Eqs. (5)-(7), as $\mathrm{Cu}(\mathrm{OH})_{2}$ is an intermediate component in the oxidation of $\mathrm{Cu}_{2} \mathrm{O}$ to $\mathrm{CuO}$. Therefore, it is quite acceptable that the nanostructures are composed of a crystalline oxide core coated by an amorphous shell made of cupric hydroxide.

Another compound that was found in a crystalline form in the anodically grown films was malachite, $\mathrm{Cu}_{2} \mathrm{CO}_{3}(\mathrm{OH})_{2}$. It was found only for the sample anodized at $19 \mathrm{~V}$ and only one plane was identified, namely (110), but the presence of carbon was also noticed by XPS analysis. Therefore, carbonate anions from the electrolyte are adsorbed and incorporated into the growing nanostructured oxides (XPS), similarly to the incorporation of acidic anions during aluminum anodizing [45]. In this particular case, the complex compound malachite was identified, whereas for anions incorporation in the case of anodic alumina, simple salts like aluminum phosphate or sulphates are formed. Therefore, the present XPS study confirms the presence of carbon species (originating from carbonates in the electrolyte), but only in one, individual case malachite was detected.

\subsubsection{Raman spectroscopy}

Raman spectroscopy examination of the samples also reveals the presence of both oxides. Noticeable peaks in the range of $274-289 \mathrm{~cm}^{-1}$ Raman shift confirmed the presence of $\mathrm{CuO}$ in all the samples. Analogous peaks, in the range of $288-300 \mathrm{~cm}^{-1}$ were reported in Refs. [46,47], also confirming the presence of cupric oxide in the anodic film [47]. Additionally, the presence of $\mathrm{CuO}$ was confirmed by peaks in the range of $325-339 \mathrm{~cm}^{-1}$. These correspond to reported literature values in the range of $321-350 \mathrm{~cm}^{-1}$ for $\mathrm{CuO}$ [48]. For the sample anodized at $30 \mathrm{~V}$, a distinct peak at $441 \mathrm{~cm}^{-1}$ revealed a significant presence of $\mathrm{Cu}_{2} \mathrm{O}$ in the nanostructures [49]. Furthermore, there are also quite broad and low intensive peaks in the range of $530-533 \mathrm{~cm}^{-1}$, also confirming the presence of $\mathrm{CuO}[47,48]$ or attributed to $\mathrm{Cu}(\mathrm{OH})_{2}$ [50]. In the range of $613-635 \mathrm{~cm}^{-1}$, there is a broad band where $\mathrm{Cu}_{2} \mathrm{O}$ and $\mathrm{CuO}$ signals overlap [48]. Therefore, according to the data acquired from Raman spectroscopy, it can be stated that $\mathrm{CuO}$ is the dominant compound in the anodically grown nanostructures. These findings are in line with the XRD data, where the greater the anodizing voltage, the greater the ratio of $\mathrm{CuO}$ to $\mathrm{Cu}_{2} \mathrm{O}$ and at the greatest voltage the $\mathrm{CuO}$ share in the crystalline phases reaches $75 \%$ (Fig. SI 2).

Anodization of copper in $0.1 \mathrm{M} \mathrm{Na}_{2} \mathrm{CO}_{3}$ electrolyte allowed to explore new experimental conditions, at lower $\mathrm{pH}$ of electrolyte than commonly applied, resulting in the formation of densely-packed, free-standing nanorods, in contrast to commonly achieved high-aspect ratio nanoneedles, that are usually collapsed under their own weight. The obtained nanorods represent a promising and favorably active surface morphology for catalytic and electrochemical process applications like photocatalytic water splitting and electrochemical carbon dioxide reduction reaction.

\section{Conclusions}

Anodization of copper in sodium carbonate aqueous solution allows 
to form crystalline nanorods made of $\mathrm{CuO}, \mathrm{Cu}_{2} \mathrm{O}$ and $\mathrm{Cu}(\mathrm{OH})_{2}$. Conducted research showed that the formation of nanostructured oxides is possible in less alkaline electrolytes that still provide passivity according to the Pourbaix diagram. The major findings of the conducted research can be listed as following:

- Copper can be effectively anodized in $0.1 \mathrm{M} \mathrm{Na}_{2} \mathrm{CO}_{3}$ at voltage ranging from $3 \mathrm{~V}$ to $31 \mathrm{~V}$.

- There is no linear relation between nanostructure diameter and voltage, however for the higher voltage, the average diameter of the obtained nanorods is greater.

- Nanostructured anodic copper consists of crystalline $\mathrm{CuO}$ and $\mathrm{Cu}_{2} \mathrm{O}$ coated with amorphous $\mathrm{Cu}(\mathrm{OH})_{2}$, according to XPS, XRD and Raman spectroscopy analyses. The performed studies show that the greater the anodizing voltage, the greater the relative amount of $\mathrm{CuO}$ vs. $\mathrm{Cu}_{2} \mathrm{O}$ in the grown nanostructures.

- XPS and XRD data reveal the incorporation of carbonates from the electrolyte into the anodic nanostructures; $\mathrm{XRD}$ analysis also reveals the formation of malachite, $\mathrm{Cu}_{2} \mathrm{CO}_{3}(\mathrm{OH})_{2}$.

\section{Acknowledgements}

W.J. Stępniowski and W.Z. Misiolek acknowledge generous support provided by the Loewy Institute at Lehigh University. Additionally, W.J. Stępniowski would like to express his appreciation to The Kościuszko Foundation, New York, NY, USA for co-sponsoring his fellowship at Lehigh University. M. Michalska-Domańska cordially acknowledges financial support from the Polish Ministry of Science and Higher Education (Scholarship for Young, Outstanding Researchers 2016-2019, agreement no. 1013/E-410/STYP/11/2016). S.T. Abrahami acknowledges funding from the Fonds Wetenschappelijk Onderzoek in Flanders (FWO, postdoctoral grant 12Z2418N).

\section{Appendix A. Supplementary data}

Supplementary data to this article can be found online at https:// doi.org/10.1016/j.jelechem.2019.113628.

\section{References}

[1] Ch Girginov, S. Kozhukharov, M. Milanes, M. Machkova, Impact of the anodizing duration on the surface morphology and performance of A2024-T3 in a model corrosive medium, Mater. Chem. Phys. 198 (2017) 137.

[2] S. Kozhukharov, Ch Girginov, I. Avramova, M. Machkova, Anodic galvanostatic polarization of AA2024-T3 aircraft alloy in conventional mineral acids, Mater. Chem. Phys. 180 (2016) 301.

[3] H. Masuda, K. Fukuda, Ordered metal nanohole arrays made by a two-step replication of honeycomb structures of anodic alumina, Science 268 (1995) 1466.

[4] C.T. Sousa, D.C. Leitao, M.P. Proenca, J. Ventura, A.M. Pereira, J.P. Araujo, Nanoporous alumina as templates for multifunctional applications, Appl. Phys. Rev. 1 (2014), 031102.

[5] M. Nemati, A. Santos, D. Losic, Fabrication and optimization of bilayered nanoporous anodic alumina structures as multi-point interferometric sensing platform, Sensors 18 (2018) 470.

[6] E. Wierzbicka, G.D. Sulka, Fabrication of highly ordered nanoporous thin Au films and their application for electrochemical determination of epinephrine, Sens. Actuators B Chem. 222 (2016) 270.

[7] Y. Chen, A. Santos, D. Ho, Y. Wang, T. Kumeria, J. Li, C. Wang, D. Losic, On the generation of interferometric colors in high purity and technical grade Aluminum: an alternative green process for metal finishing industry, Electrochim. Acta 174 (2015) 672.

[8] T. Kikuchi, O. Nishinaga, S. Natsui, R.O. Suzuki, Polymer nanoimprinting using an anodized aluminum mold for structural coloration, Appl. Surf. Sci. 341 (2015) 19.

[9] D. Nakajima, T. Kikuchi, S. Natsui, R.O. Suzuki, Mirror-finished superhydrophobic aluminum surfaces modified by anodic alumina nanofibers and self-assembled monolayers, Appl. Surf. Sci. 440 (2018) 506.

[10] J.G. Buijnsters, R. Zhong, N. Tsyntsaru, J.P. Celis, Surface wettability of macroporous anodized aluminum oxide, ACS Appl. Mater. Interfaces 5 (2013) 3224.

[11] M. Paulose, K. Shankar, O.K. Varghese, G.K. Mor, B. Hardin, C.A. Grimes, Backside illuminated dye-sensitized solar cells based on titania nanotube array electrodes, Nanotechnology 17 (2006) 1446.
[12] X. Zhang, F. Han, B. Shi, S. Farsinezhad, G.P. Dechaine, K. Shankar, Photocatalytic conversion of diluted $\mathrm{CO}_{2}$ into light hydrocarbons using periodically modulated multiwalled nanotube arrays, Angew. Chem. Int. Ed. 51 (2012) 12732.

[13] N.K. Allam, K. Shankar, C.A. Grimes, Photoelectrochemical and water photoelectrolysis properties of ordered $\mathrm{TiO}_{2}$ nanotubes fabricated by $\mathrm{Ti}$ anodization in fluoride-free $\mathrm{HCl}$ electrolytes, J. Mater. Chem. 18 (2008) 2341.

[14] A. Pawlik, R.P. Socha, M. Hubalek Kalbacova, G.D. Sulka, Surface modification of nanoporous anodic titanium dioxide layers for drug delivery systems and enhanced SAOS-2 cell response, Colloids Surfaces B Biointerfaces 171 (2018) 58.

[15] T. Kikuchi, J. Kawashima, S. Natsui, R.O. Suzuki, Fabrication of porous tungsten oxide via anodizing in an ammonium nitrate/ethylene glycol/water mixture for visible light-driven photocatalyst, Appl. Surf. Sci. 422 (2017) 130.

[16] Y.W. Choi, S. Kim, M. Seong, H. Yoo, J. Choi, $\mathrm{NH}_{4}$-doped anodic $\mathrm{WO}_{3}$ prepared through anodization and subsequent $\mathrm{NH}_{4} \mathrm{OH}$ treatment for water splitting, Appl. Surf. Sci. 324 (2015) 414.

[17] W.J. Stępniowski, W.Z. Misiołek, Review of fabrication methods, physical properties, and applications of nanostructured copper oxides formed via electrochemical oxidation, Nanomaterials 8 (2018) 379.

[18] W.J. Stępniowski, S. Stojadinović, R. Vasilić, N. Tadić, K. Karczewski, S.T. Abrahami, J.G. Buijnsters, J.M.C. Mol, Morphology and photoluminescence of nanostructured oxides grown by copper passivation in aqueous potassium hydroxide solution, Mater. Lett. 198 (2017) 89.

[19] L. Shooshtari, R. Mohammadpour, A.I. Zad, Enhanced photoelectrochemical processes by interface engineering, using $\mathrm{Cu}_{2} \mathrm{O}$ nanorods, Mater. Lett. 163 (2016) 81.

[20] Z. Cheng, D. Ming, K. Fu, N. Zhang, K. Sun, pH-controllable water permeation through a nanostructured copper mesh film, ACS Appl. Mater. Interfaces 4 (2012) 5826.

[21] X. Wu, H. Bai, J. Zhang, F. Chen, G. Shi, Copper hydroxide nanoneedle and nanotube arrays fabricated by anodization of copper, J. Phys. Chem. B 109 (2005) 22836.

[22] F. Xiao, S. Yuan, B. Liang, G. Li, S.O. Pehkonen, T.J. Zhang, Superhydrophobic CuO nanoneedle-covered copper surfaces for anticorrosion, J. Mater. Chem. 3 (2015) 4374.

[23] A.S. Zoolfakar, R.A. Rani, A.J. Morfa, A.P. O'Mullane, K. Kalantar-Zadeh, Nanostructured copper oxide semiconductors: a perspective on materials, synthesis methods and applications, J. Mater. Chem. C 2 (2014) 5247.

[24] K.P. Musselman, A. Wisnet, D.C. Iza, H.C. Hesse, C. Scheu, J.L. MacManus-Driscoll, L. Schmidt-Mende, Strong efficiency improvements in ultra-low-cost inorganic nanowire solar cells, Adv. Mater. 22 (2010), E254.

[25] T.G. Satheesh Babu, T. Ramachandran, Development of highly sensitive nonenzymatic sensor for the selective determination of glucose and fabrication of a working model, Electrochim. Acta 55 (2010) 1612.

[26] J. Wu, X. Li, B. Yadian, H. Liu, S. Chun, B. Zhang, K. Zhou, C.L. Gan, Y. Huang, Nano-scale oxidation of copper in aqueous solution, Electrochem. Commun. 26 (2013) 21.

[27] W. Jiang, J. He, F. Xiao, S. Yuan, H. Lu, B. Liang, Preparation and antiscaling application of superhydrophobic anodized $\mathrm{CuO}$ nanowire surfaces, Ind. Eng. Chem. Res. 54 (2015) 6874.

[28] F. Caballero-Briones, A. Palacios-Padrós, O. Calzadilla, F. Sanz, F., Evidence and analysis of parallel growth mechanisms in $\mathrm{Cu} 2 \mathrm{O}$ films prepared by $\mathrm{Cu}$ anodization, Electrochim. Acta 55 (2010) 4353.

[29] B. Beverskog, I. Puigdomenech, Revised Pourbaix diagrams for copper at 25 to 300 ${ }^{\circ} \mathrm{C}$, J. Electrochem. Soc. 144 (1997) 3476.

[30] W.J. Stępniowski, D. Paliwoda, Z. Chen, K. Landskron, W.Z. Misiolek, Hard anodization of copper in potassium carbonate aqueous solution, Mater. Lett. 252 (2019) 182-185.

[31] I.V. Roslyakov, E.O. Gordeeva, K.S. Napolskii, Role of electrode reaction kinetics in self-ordering of porous anodic alumina, Electrochim. Acta 241 (2017) 362.

[32] V. Vega, J. García, J.M. Montero-Moreno, B. Hernando, J. Bachmann, V.M. Prida, K. Nielsch, Unveiling the hard anodization regime of aluminum: insight into nanopores self-organization and growth mechanism, ACS Appl. Mater. Interfaces 7 (2015) 28682.

[33] V.P. Parkhutik, V.I. Shershulsky, Theoretical modelling of porous oxide growth on aluminium, J. Phys. D Appl. Phys. 25 (1992) 1258.

[34] M.R. Gennero de Chiavlo, J.O. Zerbino, S.L. Marchiano, A.J. Arvia, Correlation of electrochemical and elipsometric data in relation to the kinetics and mechanism of $\mathrm{Cu}_{2} \mathrm{O}$ electroformation in alkaline solutions, J. Appl. Electrochem. 16 (1986) 517.

[35] H.H. Uhlig, Passivity in metals and alloys, Corros. Sci. 19 (1979) 777.

[36] W.J. Stepniowski, M. Moneta, K. Karczewski, M. Michalska-Domanska, T. Czujko, J.M.C. Mol, J.G. Buijnsters, Fabrication of copper nanowires via electrodeposition in anodic aluminum oxide templates formed by combined hard anodizing and electrochemical barrier layer thinning, J. Electroanal. Chem. 809 (2018) 59.

[37] W.J. Stępniowski, Z. Bojar, Synthesis of anodic aluminum oxide (AAO) at relatively high temperatures. Study of the influence of anodization conditions on the alumina structural features, Surf. Coat. Technol. 206 (2011) 265.

[38] G.D. Sulka, K.G. Parkoła, Temperature influence on well-ordered nanopore structures grown by anodization of aluminium in sulphuric acid, Electrochim. Acta 52 (2007) 1880.

[39] J. Ghijsen, L.H. Tjeng, J. van Elp, H. Eskes, J. Westerink, G.A. Sawatzky, M.T. Czyzyk, Electronic structure of $\mathrm{Cu}_{2} \mathrm{O}$ and CuO, Phys. Rev. B 38 (1998) 11322.

[40] B. Millet, C. Fiaud, C. Hinnen, E.M.M. Sutter, A correlation between electrochemical behaviour, composition and semiconducting properties of naturally grown oxide films on copper, Corros. Sci. 37 (1995) 1903.

[41] O. Akhavan, R. Azimirad, S. Safa, E. Hasani, $\mathrm{CuO} / \mathrm{Cu}(\mathrm{OH})_{2}$ hierarchical nanostructures as bactericidal photocatalysts, J. Mater. Chem. 21 (2011) 9634. 
[42] A.I. Stadnichenko, A.M. Sorokin, A.I. Boronin, XPS, UPS, and STM studies of nanostructured CuO films, J. Struct. Chem. 49 (2008) 341.

[43] T. Masuda, H. Asoh, S. Haraguchi, S. Ono, Fabrication and characterization of single phase $\alpha$-alumina membranes with tunable pore diameters, Materials 8 (2015) 1350.

[44] S. Sreekantan, R. Hazan, Z. Lockman, Photoactivity of anatase-rutile $\mathrm{TiO}_{2}$ nanotubes formed by anodization method, Thin Solid Films 518 (2009) 16.

[45] H. Tsuchiya, J.M. Macak, L. Taveira, P. Schmuki, Fabrication and characterization of smooth high aspect ratio zirconia nanotubes, Chem. Phys. Lett. 410 (2005) 188

[46] F. Le Coz, L. Arurault, L. Datas, Chemical analysis of a single basic cell of porous anodic aluminium oxide templates, Mater. Char. 61 (2010) 283.

[47] D.P. Oyarzún Jerez, M.L. Teijelo, W.R. Cervantes, O.E. Linarez Pérez, J. Sánchez, G.D. Pizarro, G. Acosta, M. Flores, R. Arratia-Perez, Nanostructuring of anodic copper oxides in fluoride-containing ethylene glycol media, J. Electroanal. Chem. 807 (2017) 181.

[48] Y. Deng, A.D. Handoko, Y. Du, S. Xi, B.S. Yeo, In situ Raman spectroscopy of copper and copper oxide surfaces during electrochemical oxygen evolution reaction: identification of CuIII oxides as catalytically active species, ACS Catal. 6 (2016) 2473.

[49] P. Wang, Y.H. Ng, R. Amal, Embedment of anodized p-type Cu2O thin films with $\mathrm{CuO}$ nanowires for improvement in photoelectrochemical stability, Nanoscale 5 (2013) 2952.

[50] J.C. Hamilton, J.C. Farmer, R.J. Anderson, In situ Raman spectroscopy of anodic films formed on copper and silver in sodium hydroxide solution, J. Electrochem. Soc. 133 (1986) 739. 